\title{
Neonatal Ventral Hippocampal Lesions Produce an Elevation of $\Delta$ FosB-Like Protein(s) in the Rodent Neocortex
}

\author{
Kelly J Powell ${ }^{1,5}$, Tammy L Binder ${ }^{2,5}$, Sarah Hori', Yusaku Nakabeppu ${ }^{3}$, Daniel R Weinberger ${ }^{4}$, \\ Barbara K Lipska ${ }^{4}$ and George S Robertson*, I \\ 'Departments of Psychiatry and Pharmacology, Faculty of Medicine, Dalhousie University, Halifax, NS, Canada; ${ }^{2}$ Department of Psychiatry, \\ Beth Israel Deaconess Medical Center, Boston, MA, USA; ${ }^{3}$ Division of Neurofunctional Genomics, Department of Immunobiology and \\ Neuroscience, Medical Institute of Bioregulation, Kyushu University, Higashi-ku, Japan; ${ }^{4}$ Clinical Brain Disorders Branch, \\ Intramural Research Program, National Institute of Mental Health, National Institutes of Health, Bethesda, MD, USA
}

\begin{abstract}
Rats that have sustained bilateral excitotoxic lesions of the ventral hippocampus $(\mathrm{VH})$ as neonates develop behavioral abnormalities as adults (hyper-responsiveness to stress, diminished prepulse inhibition, and increased sensitivity to dopamine agonists), which resemble certain aspects of schizophrenia. Although this behavioral profile is thought to reflect dysregulation of the mesolimbic dopamine system, the precise neuroanatomical and neurochemical substrates that mediate the emergence of these abnormalities during brain maturation are unclear. In order to identify putative sites responsible for the development of behavioral abnormalities following neonatal lesions of the $\mathrm{VH}$, we utilized the chronic neuronal activity marker $\Delta \mathrm{FosB}$. By comparison to sham lesioned animals, bilateral destruction of the $\mathrm{VH}$ elevated $\Delta$ FosB expression throughout the caudate putamen and neocortex of animals lesioned as neonates. These increases were not observed in rats lesioned as young-adults, suggesting that $\Delta \mathrm{FosB}$ induction in the cortex of neonatally lesioned rats may be related to altered cortical neurodevelopment. Accumulating evidence implicates $\Delta \mathrm{Fos} B$ in mediation of the long-lasting effects of altered dopaminergic neurotransmission on behavior. The present findings are consistent with this proposal and suggest that elevated expression of $\Delta$ FosB identifies overactive neurons that may contribute to the enhanced sensitivity to stress and dopaminergic agonists of rats that have sustained bilateral ventral hippocampal lesions as neonates.
\end{abstract}

Neuropsychopharmacology (2006) 31, 700-7II. doi:I0.1038/sj.npp. 1300883; published online 31 August 2005

Keywords: schizophrenia; neurodevelopment; immediate-early genes; neonatal lesion; hippocampus; cerebral cortex

\section{INTRODUCTION}

The neurodevelopmental hypothesis of schizophrenia posits that clinical symptoms (which typically emerge in early adulthood) might be late consequences of an early defect in brain development (Walker and Neumann, 1996; Weinberger, 1987, 1996). Post-mortem cytoarchitectural abnormalities in the temporal lobe as well as the hippocampus and several other limbic regions suggestive of arrested neuronal migration during the second or third trimester of prenatal development provide the strongest evidence for developmental neuropathology in schizophrenia (Akbarian et al,

\footnotetext{
*Correspondence: Dr GS Robertson, Departments of Psychiatry and Pharmacology, Faculty of Medicine, Dalhousie University, Sir Charles Tupper Medical Building, 5850 College Street, Halifax, Nova Scotia Canada B3H IX5, Tel: + I 902494 1528, Fax: + I 902494 I388,

E-mail: George.Robertson@dal.ca

${ }^{5}$ These authors contributed equally to this work.

Received 7 March 2005; revised I June 2005; accepted 27 July 2005 Online publication: 29 July 2005 at http://www.acnp.org/citations/ Npp072905050 I57/default.pdf
}

1993a, b; Arnold et al, 1991; Falkai and Bogarts, 1996; Jakob and Beckmann, 1986; Weinberger, 1996). The neurodevelopmental hypothesis challenges commonly held assumptions that brain lesions lead to immediate impairments of function, which may improve with time, and that the possibility of functional recovery may be higher following certain types of lesions that occur early in life because of the plasticity of the immature brain (Kolb and Whishaw, 1989). While these assumptions are supported by numerous studies on the effects of early brain lesions, it has been shown that early brain injuries can lead to worse functional outcomes than corresponding damage to adults. For instance, mature rats that have sustained unilateral hippocampal lesions as neonates, but not adults, display impaired spatial memory (vanPraag et al, 1996). Furthermore, non-human primates that have received perinatal lesions of the dorsolateral prefrontal cortex perform well on a working memory task prior to maturity, but lose this ability in early adulthood (Goldman, 1971). This latter observation indicates that early brain injury can result in impairment after a period of apparently normal functioning and development. 
Bilateral excitotoxic lesions of the ventral hippocampus (VH) performed on 7-day-old rat pups result in animals that develop normally in many respects until puberty, when they begin to demonstrate features reminiscent of schizophrenia: hyper-responsiveness to stress, diminished prepulse inhibition of the acoustic startle response, and increased sensitivity to dopamine agonists and NMDA antagonists (Lipska et al, 1993, 1995; Lipska and Weinberger, 1993; Al-Amin et al, 2000). This behavioral profile is presumed to reflect overactivity of the mesolimbic dopaminergic system and is ameliorated by antipsychotic drugs (Lipska and Weinberger, 1994). However, the precise neuroanatomical and neurochemical substrates that mediate the emergence of these behaviors during development have yet to be established.

The fos and jun families of immediate-early genes (IEGs) encode transcription factors that alter target gene expression in response to extracellular stimuli (Morgan and Curran, 1989; Sheng and Greenberg, 1990). Fos, the protein product of $c$-fos, has been used as a marker of neuronal activity in order to map functional pathways throughout the CNS (Dragunow and Faull, 1989; Morgan and Curran, 1991; Sagar et al, 1988). However, c-fos mapping is limited by the fact that repeated neuronal stimulation results in a rapid loss of the acute $c$-fos response (Hope et al, 1994b; Rosen et al, 1994). Another inducible transcription factor, $\Delta$ FosB, a truncated version of FosB generated by alternative splicing of the fos $B$ transcript (Mumberg et al, 1991; Nakabeppu and Nathans, 1991), has been found to have prolonged induction characteristics and may be a marker of chronic activation (Doucet et al, 1996; Hiroi et al, 1997; Mandelzys et al, 1997; Mumberg et al, 1991; Nakabeppu and Nathans, 1991).

The goal of the present study was to compare $\Delta \mathrm{FosB}$ expression in animals undergoing bilateral $\mathrm{VH}$ lesions as neonates with animals lesioned as young-adults in order to identify neuroanatomical sites that may be involved in the hyperdopaminergic behavioral profile observed in adulthood, after neonatal brain lesions.

\section{MATERIALS AND METHODS}

\section{Animals and Experimental Protocols}

One group of neonatal rats sustained bilateral excitotoxic $\mathrm{VH}$ lesions (see below) on postnatal day (PD) 7 while another group of rat pups underwent bilateral sham lesions. On PD25, animals were weaned, separated by lesion status, and grouped two to three to a cage until being killed on PD56 (7 weeks after the lesion or sham surgery described below). A third group consisted of young-adult rats that underwent bilateral excitotoxic VH lesions on PD42, while another eight young-adult rats sustained bilateral sham lesions. All of these animals were killed on PD70 (4 weeks after the sham or lesion surgery, which is described below). All animals were killed by deep anesthesia with pentobarbital $(100 \mathrm{mg} / \mathrm{kg}$, i.p.), immediately followed by intracardial perfusion with $150 \mathrm{ml}$ of saline $(0.9 \%)$ followed by $200 \mathrm{ml}$ of $0.1 \mathrm{M}$ phosphate buffer containing $4 \%$ paraformaldehyde. Brains were postfixed for several hours and then transferred to cold $10 \%$ sucrose in $100 \mathrm{mM}$ sodium phosphate buffer for several days. Sections $20 \mu \mathrm{m}$ thick were cut on a cryostat.
Hippocampal sections were stained with cresyl violet to verify the size and location of the lesion.

\section{Neonatal Ventral Hippocampal Lesions}

Bilateral lesions of the $\mathrm{VH}$ were performed on neonatal rats as described previously by Lipska et al (1993). Pregnant Sprague-Dawley rats obtained at 12-15 days of gestation (Zivic-Miller Labs, Zelienople, PA) were housed individually in breeding cages with a $12 \mathrm{~h}$ light/dark cycle and fed ad libitum. Litters of four to eight male pups were formed. On PD7 (weight 15-18g), pups were randomly assigned to lesion or sham status and anesthetized by hypothermia by placement on ice for 10-20 min. Pups were then taped to a platform fixed to a stereotaxic Kopf instrument and an incision was made in the skin overlying the skull. Bilateral $\mathrm{VH}$ lesions were made by infusing $0.3 \mu \mathrm{l}$ of ibotenic acid (10 $\mu \mathrm{g} / \mu \mathrm{l}$; Sigma) (lesion) or artificial cerebrospinal fluid (CSF) (sham) through a Hamilton needle at the coordinates (in $\mathrm{mm}$ ) anteroposterior (AP) -3.0, mediolateral (ML) \pm 3.5 , relative to bregma, and dorsoventral (DV) $-5.0 \mathrm{~mm}$, relative to the skull. Injections were made using an infusion pump at a rate of $0.15 \mu \mathrm{l} / \mathrm{min}$ (followed by $4 \mathrm{~min}$ of rest prior to withdrawing the needle). Pups were placed under warming lamps and then returned to their mothers.

\section{Young-Adult Ventral Hippocampal Lesions}

Young-adult VH lesions were performed on PD42 male Sprague-Dawley rats (weight $220-240 \mathrm{~g}$ ) as described by Lipska et al (1992). Briefly, rats were anesthetized with Equithesin ( $3 \mathrm{ml} / \mathrm{kg}$, i.p.) and placed in a Kopf stereotaxic instrument. Ibotenic acid ( $6 \mu \mathrm{g} / 0.6 \mu \mathrm{l}$, over $3 \mathrm{~min}$ ) (lesion) or an equal volume of artificial CSF (sham) was infused bilaterally (two injections on each side) through a 26-gauge stainless steel cannula at the coordinates (in mm) AP -4.4, $\mathrm{ML} \pm 5.0$ relative to bregma, and DV -8.0 and $-6.0 \mathrm{~mm}$ relative to dura.

\section{Antisera and Immunohistochemistry}

FosB-like immunoreactivity was detected using two different affinity-purified rabbit polyclonal antibodies. The FosB $(\mathrm{N})$ antibody was raised against amino acids 79-131 of the $\mathrm{N}$-terminus of FosB and recognizes both FosB and $\triangle$ FosB. The $\operatorname{Fos} B(C)$ antibody was raised against amino acids $245-315$ of the C-terminus of FosB. Since the C-terminus is missing from $\Delta$ FosB, the Fos $(\mathrm{C})$ antibody only recognizes FosB (Nakabeppu and Nathans, 1991; Nakabeppu et al, 1993). Purification of the FosB(N) antibody by affinity chromatography of antisera on antigen columns and the establishment of its selectivity by Western blotting and immunoprecipitation experiments have been described previously (Nakabeppu and Nathans, 1991; Nakabeppu et al, 1993). Immunohistochemistry was performed using a standard procedure described previously by Robertson and Fibiger (1992). Sections $20 \mu \mathrm{m}$ thick were washed in $0.02 \mathrm{M}$ phosphate-buffered saline (PBS) containing $0.3 \%$ hydrogen peroxide for $10 \mathrm{~min}$ to block endogenous peroxidase activity. Sections were then washed three times in PBS and incubated in PBS containing 0.3\% Triton X-100, $0.02 \%$ azide, and $\operatorname{Fos} \mathrm{B}(\mathrm{N})(1: 1500)$ primary antisera for 
$48 \mathrm{~h}$. Next, the sections were washed three times with PBS and incubated with biotin-labelled donkey anti-rabbit secondary antisera ( $1: 200$; Jackson Laboratories) for $16 \mathrm{~h}$. The sections were washed three more times with PBS and incubated for $3 \mathrm{~h}$ with PBS containing $0.3 \%$ Triton X-100 and streptavidin-horseradish peroxidase (1:100; Amersham). After three further washes in PBS, the sections were rinsed in $0.1 \mathrm{M}$ acetate buffer, $\mathrm{pH}$ 6.0. The reaction was visualized using a glucose oxidase-diaminobenzidinenickel method. The reaction was terminated by washing in acetate buffer, and the sections were mounted on chrome alum-coated slides. After drying, the sections were dehydrated through a graded series of alcohol and two changes of xylene, and coverslipped for microscopic observation.

\section{Counting of Immunoreactive Cells}

Images of $\operatorname{FosB}(\mathrm{N})$-like immunoreactivity in the cortex, caudate putamen, and nucleus accumbens were taken using a $\times 5$ objective and an Axiocam HRc digital imaging camera and software package (AxioVision, Zeiss). Brain sections illustrating the areas $(600 \times 800 \mu \mathrm{m})$ used for cell counts in the cortex, nucleus accumbens (core and shell), and caudate putamen (medial and lateral regions) are shown in Figure 1. FosB(N)-like immunoreactivity was quantified in these regions by counting the number of immunoreactive nuclei using ScionImage Software. In all cases, cell counts were performed on 3-4 sections spaced approximately $120 \mu \mathrm{m}$ apart by an observer unaware of the treatment condition.

\section{Isolation of Nuclear Protein}

Nuclear proteins were extracted from each rat cortex according to the methods previously described (Doucet et al, 1996). Each cortex was homogenized using a dounce homogenizer (loose pestle, 15 strokes) in $1 \mathrm{ml}$ of Buffer A $(0.25 \mathrm{M}$ sucrose, $0.05 \mathrm{M}$ Tris- $\mathrm{HCl}(\mathrm{pH} 6.8), 0.025 \mathrm{M} \mathrm{NaCl}$, $4 \mathrm{mM} \mathrm{MgCl}, 1 \mathrm{mM} \mathrm{EGTA}$, and the following protease inhibitors added just before use: Roche Complete Protease Inhibitor tablet (Roche Applies Sciences, Laval, Quebec, Canada) and $1 \mathrm{mM}$ PMSF). Samples were centrifuged at $11000 \mathrm{~g}$ for $20 \mathrm{~s}$ and resuspended in $250 \mu \mathrm{l}$ of Buffer A containing $1 \%$ Triton X-100. Following an incubation for $5 \mathrm{~min}$ at $4^{\circ} \mathrm{C}$, samples were dounce homogenized (tight pestle, 20 strokes) and the nuclei were pelleted by centrifugation at $11000 \mathrm{~g}$ for $20 \mathrm{~s}$. Each pellet was resuspended in $60 \mu$ lof Buffer B $(0.75 \mathrm{M} \mathrm{NaCl}, 0.05 \mathrm{M}$ HEPES ( $\mathrm{pH}$ 7.9), $12.5 \%$ glycerol, $0.75 \mathrm{mM} \mathrm{MgCl}, 0.5 \mathrm{mM}$ EGTA, $5 \mathrm{mM}$ dithiothreitol, plus protease inhibitors), vortexed, and incubated at $4{ }^{\circ} \mathrm{C}$ for $45 \mathrm{~min}$. Nuclear extracts were collected following centrifugation at $13000 \mathrm{~g}$ for $15 \mathrm{~min}$ at $4{ }^{\circ} \mathrm{C}$.

\section{Western Blotting}

Cortical nuclear protein extracts $(20 \mu \mathrm{g})$ were separated on $10 \%$ SDS-polyacrylamide gels. Protein was then transferred to PVDF membranes, blocked for $1 \mathrm{~h}$ in $1 \%$ milk powder in Tris-buffered saline containing $0.05 \%$ Tween 20 (TBS-T), and incubated in polyclonal anti-FosB antibody $(1: 200$; Santa Cruz) overnight at $4^{\circ} \mathrm{C}$. Membranes were then rinsed in TBS-T and incubated in a horseradish peroxidase-
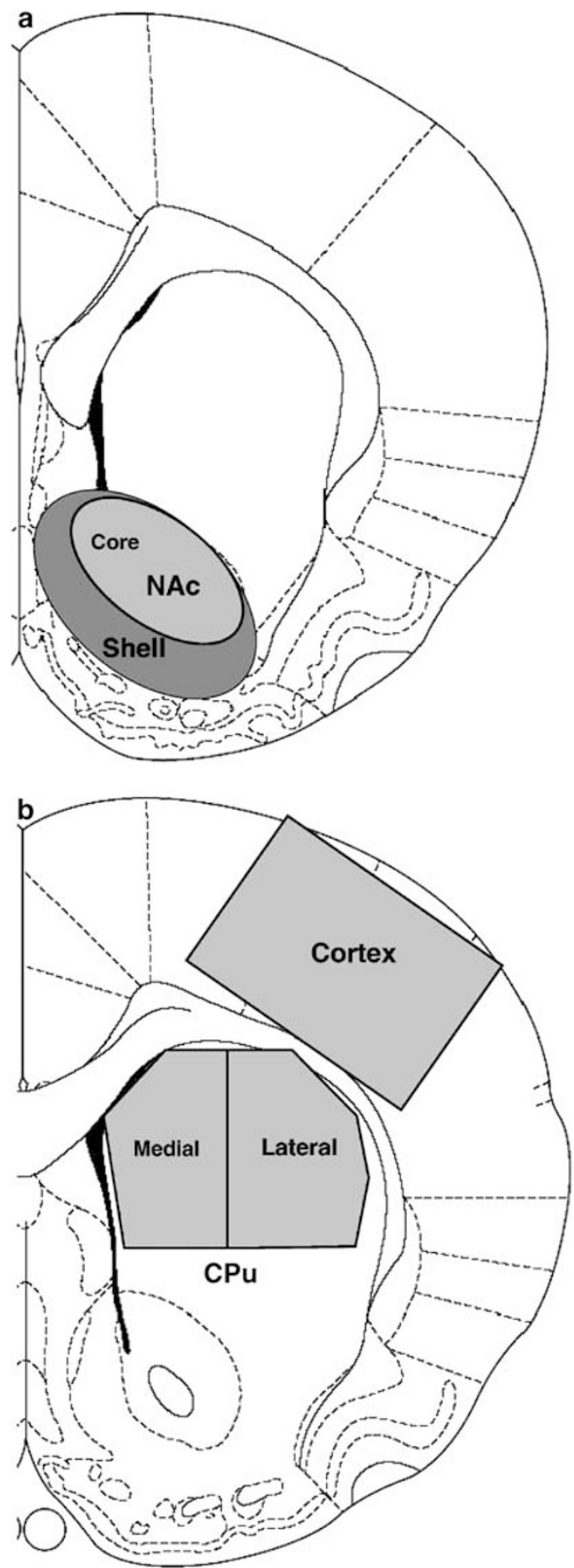

Figure I Camera lucida drawings of representative sections used for the counting of $\Delta$ FosB-like immunoreactive neurons in the nucleus accumbens (a), and caudate putamen and cortex (b). Shaded boxes indicate the sampled areas used for counting.

conjugated anti-rabbit antibody $(1: 5000$; BD Transduction Laboratories) for $1 \mathrm{~h}$ at room temperature. Following washes in TBS-T, the membranes were incubated with ECL-plus reagent (Amersham Biosciences, Quebec, Canada) and scanned using a Storm imaging system (Amersham Biosciences). Membranes were then stripped according to the manufacturer's recommendations (ECL-plus reagent, 
Amersham Biosciences), incubated in $5 \%$ milk powder in TBS-T for $10 \mathrm{~min}$, and incubated in monoclonal anti- $\beta$-actin antibody (Sigma) overnight at $4^{\circ} \mathrm{C}$. Following washes in TBS-T, membranes were incubated in a peroxidaseconjugated anti-mouse antibody (1:10 000; Vector Laboratories) for $1 \mathrm{~h}$ at room temperature, washed in TBS-T, incubated with ECL-plus reagent, and rescanned using the Storm imaging system. ImageQuant software (Amersham Biosciences) was used to determine the optical density of protein bands and all data were normalized to the expression of $\beta$-actin.

\section{Statistical Analysis}

The number of $\operatorname{FosB}(\mathrm{N})$-immunoreactive nuclei observed in the neonate sham, neonate lesion, young-adult sham, and young-adult lesion groups were compared using a two-way analysis of variance (ANOVA) followed by a Bonferroni post hoc test, with Age (neonate and young-adult) and Lesion Status (sham and lesion) as independent variables. Results from Western blot experiments for the expression of FosB and $\Delta F o s B$ in sham and lesioned neonatal and young-adult animals were also compared using a two-way ANOVA and Bonferroni post hoc test (GraphPad Prism version 4.00 for Windows, GraphPad Software, San Diego, California, USA).

\section{RESULTS}

\section{Verification of the Lesion}

Representative cresyl violet-stained sections from adult rats that received bilateral $\mathrm{VH}$ lesions either as neonates or young-adults are shown in Figure 2. Injection of ibotenic acid into the $\mathrm{VH}$ of neonatal and young-adult rats produced a lesion of comparable size characterized by neuronal loss and atrophy (Figure $2 \mathrm{~b}$ and $\mathrm{d}$ ). These lesions were largely restricted to the $\mathrm{VH}$. Animals that displayed damage in the dorsal hippocampus were not included in the study. Animals that received sham lesions either as neonates or young-adults did not show any visible damage to the hippocampus (Figure 2a and $\mathrm{c}$ ).

\section{Effects of Bilateral Ventral Hippocampal Lesions on $\Delta$ FosB-Like Immunoreactivity in the Cortex}

Representative photomicrographs of $\operatorname{Fos} \mathrm{B}(\mathrm{N})$ immunoreactivity in the cortex of animals lesioned as neonates or young-adults are shown in Figure 3. In adult animals that received sham lesions either as neonates or young-adults, basal expression of $\operatorname{FosB}(\mathrm{N})$ immunoreactivity was low, with few $\operatorname{FosB}(\mathrm{N})$-immunoreactive neurons observed in superficial and deep layers of the cortex (Figure $3 \mathrm{a}$ and $\mathrm{c}$ ). At 7 weeks after bilateral ibotenic acid lesions of the $\mathrm{VH}$ of neonatal rats, there was a marked increase in the number of immunoreactive neurons detected with the anti-FosB(N) antibody throughout the entire neocortex (Figure 3a). Representative pictures of the sensorimotor cortex show that $\operatorname{FosB}(\mathrm{N})$ immunoreactivity was highest in deep (layers $\mathrm{V}$ and VI) and superficial cortical layers (II and III) of animals lesioned bilaterally in the $\mathrm{VH}$ as neonates (PD7; Figure 3b). Animals lesioned on PD42 (young-adult) did not show induction in the cortex 4 weeks after surgery
(Figure 3d). Very few immunoreactive neurons were detected by the $\operatorname{Fos} B(C)$ antibody in all of the four groups in this experiment. Fidelity of the $\operatorname{Fos} B(C)$ antibody was confirmed by robust immunostaining in animals that had received acute injections of clozapine or haloperidol (results not shown) and thereby served as FosB induction controls. This indicates that the observed anti-FosB(N) immunoreactivity was due to $\triangle$ FosB since FosB levels were below the limits of detection with the $\operatorname{Fos} B(C)$ antibody. The term $\Delta$ FosB-like immunoreactivity will be used from this point on to describe immunoreactivity detected with the $\operatorname{Fos} B(N)$ antibody.

Cell counts for $\Delta$ FosB-immunoreactive neurons in the cortex revealed a significant effect of Lesion $\left(\mathrm{F}_{1,15}=47.91\right.$, $P<0.0001)$, Age $\left(\mathrm{F}_{1,15}=53.83, P<0.0001\right)$, and an interaction of Age $\times$ Lesion $\left(F_{1,15}=44.78, P<0.0001\right)$. There was a massive induction of $\Delta$ FosB in the cortex of animals lesioned with ibotenic acid as neonates when compared to sham lesioned controls, with counts of $1829.8 \pm 303.4$ and $105.1 \pm 18.8$, respectively (Figure 4 ). The number of $\Delta$ FosBimmunopositive neurons observed in adult animals lesioned with ibotenic acid as young-adults was not different from controls that received sham lesions as young-adults with counts of $53.1 \pm 7.8$ and $23.9 \pm 4.8$, respectively (Figure 4 ).

To further confirm that the increased immunostaining observed with the $\operatorname{Fos} \mathrm{B}(\mathrm{N})$ antibody resulted from increased expression $\triangle F$ FosB and not FosB, Western blot analysis was performed on nuclear extracts from cortical tissue. As shown in Figure $5 \mathrm{a}$ and $\mathrm{b}$, the pan-FosB antibody recognized bands ranging from 33 to $37 \mathrm{kDa}$, representing $\triangle$ FosB and its more stable phosphorylated isoforms, and a band at $47 \mathrm{kDa}$, representing FosB. Following normalization of the optical densities of these bands to that of $\beta$-actin, quantification of $\triangle$ FosB revealed a significant effect of Lesion $\left(\mathrm{F}_{1,18}=9.764, P<0.01\right)$, Age $\left(\mathrm{F}_{1,18}=4.611, P<0.05\right)$, and an interaction of Age $\times$ Lesion $\left(\mathrm{F}_{1,18}=6.735, P<0.02\right)$. There was no significant effect of either Lesion or Age on FosB expression. Adult animals that received ibotenic acid as neonates showed a significant increase in the expression of $\Delta$ FosB as compared to sham controls (Figure 5a and d). Consistent with our immunohistochemical findings, there was no difference in the levels of FosB between neonatal sham- and ibotenic acid lesioned animals (Figure 5a and c).

Quantification of the optical densities of $\triangle F o s B$ and FosB bands, following normalization to $\beta$-actin, revealed no significant differences between young-adult sham and lesioned animals (Figure $5 \mathrm{~b}-\mathrm{d}$ ).

\section{Effect of Bilateral Ventral Hippocampal Lesions on $\Delta$ FosB-Like Immunoreactivity in the Caudate Putamen}

Similar to our findings in the cortex, few $\Delta$ FosB-immunoreactive neurons were observed in the caudate putamen of adult animals that received ibotenic acid or sham lesions as young-adults (Figure $6 \mathrm{c}$ and $\mathrm{d}$ ). $\Delta$ FosB immunoreactivity was increased only in animals lesioned with ibotenic acid as neonates (Figure 6b). Animals lesioned with ibotenic acid as young-adults did not show this induction 4 weeks after surgery (Figure $6 \mathrm{~d}$ ). Cell counts for $\Delta$ FosB-immunoreactive neurons in the medial and lateral caudate putamen are given in Figure $7 \mathrm{a}$ and $\mathrm{b}$. In the medial caudate putamen, there was a significant effect of Lesion $\left(\mathrm{F}_{1,15}=45.52\right.$, 

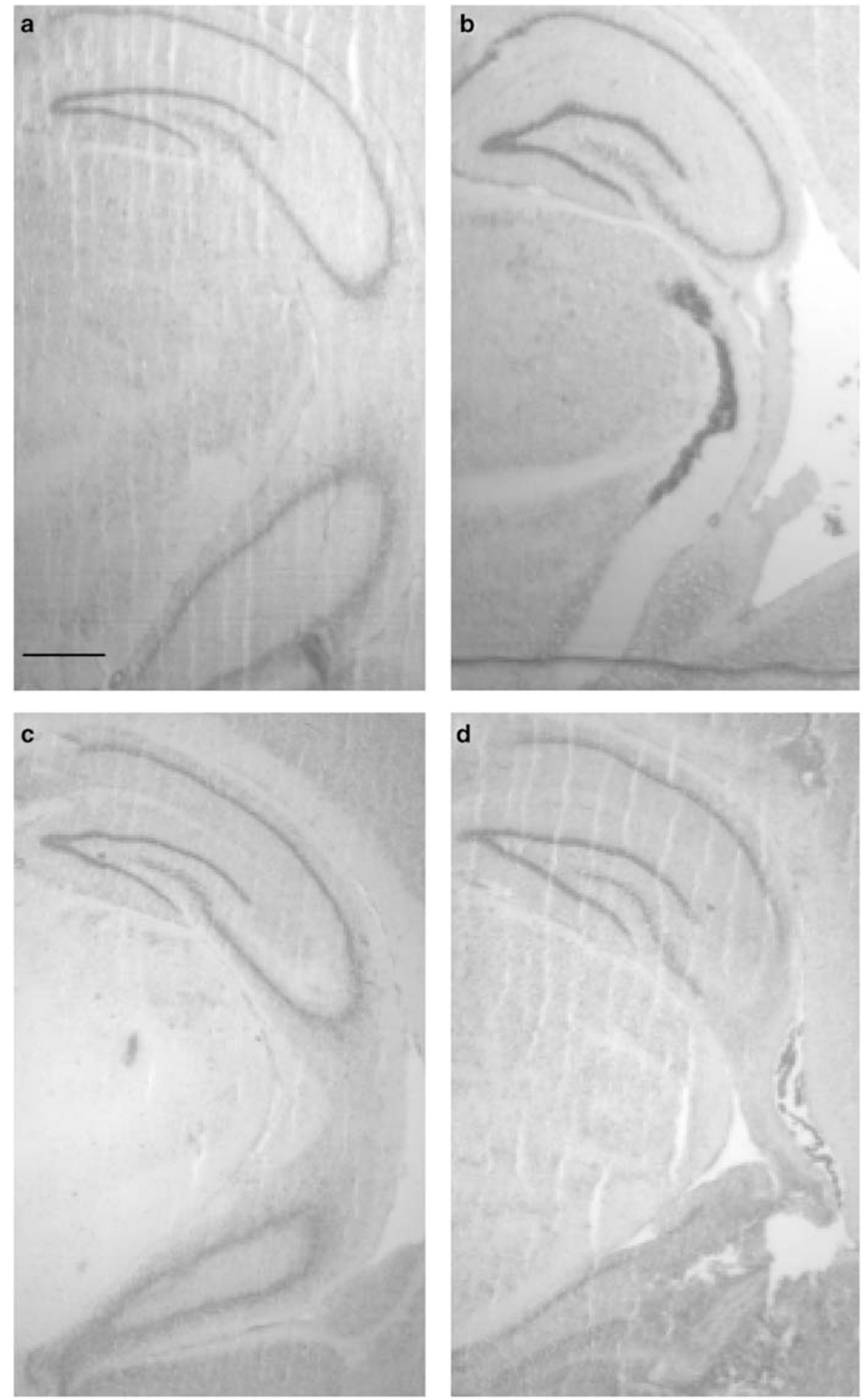

Figure 2 Representative cresyl violet-stained sections through the hippocampus of neonatal or young-adult lesioned animals: Neonatal sham (a), neonate lesion (b), young-adult sham (c), and young-adult lesion (d). Scale bar: $100 \mu \mathrm{m}$.

$P<0.0001)$, Age $\left(\mathrm{F}_{1,15}=59.60, P<0.0001\right)$, and an interaction of Age $\times$ Lesion $\left(\mathrm{F}_{1,15}=42.13, P<0.0001\right)$. Post hoc analysis revealed that animals lesioned with ibotenic acid as neonates displayed significantly more $\Delta$ FosB-like immunoreactive neurons compared to sham lesioned controls with counts of $457.7 \pm 111.8$ and $72.2 \pm 20.5$, respectively (Figure 7a). $\Delta$ FosB expression was not significantly elevated in animals lesioned as young-adults compared to sham lesioned controls with counts of $43.9 \pm 33.5$ and $36.4 \pm 28.3$, respectively (Figure $7 \mathrm{a}$ ). In the lateral caudate putamen, there was also a significant effect of Lesion $\left(\mathrm{F}_{1,15}=10.29\right.$, $P<0.01)$, Age $\left(\mathrm{F}_{1,15}=9.27, P<0.01\right)$, and an interaction of Age $\times$ Lesion $\left(\mathrm{F}_{1,15}=7.29, P<0.05\right)$. Post hoc analysis indicated that animals lesioned with ibotenic acid as neonates displayed more $\Delta$ FosB-like immunoreactive cell in the lateral region of the caudate putamen when compared to 

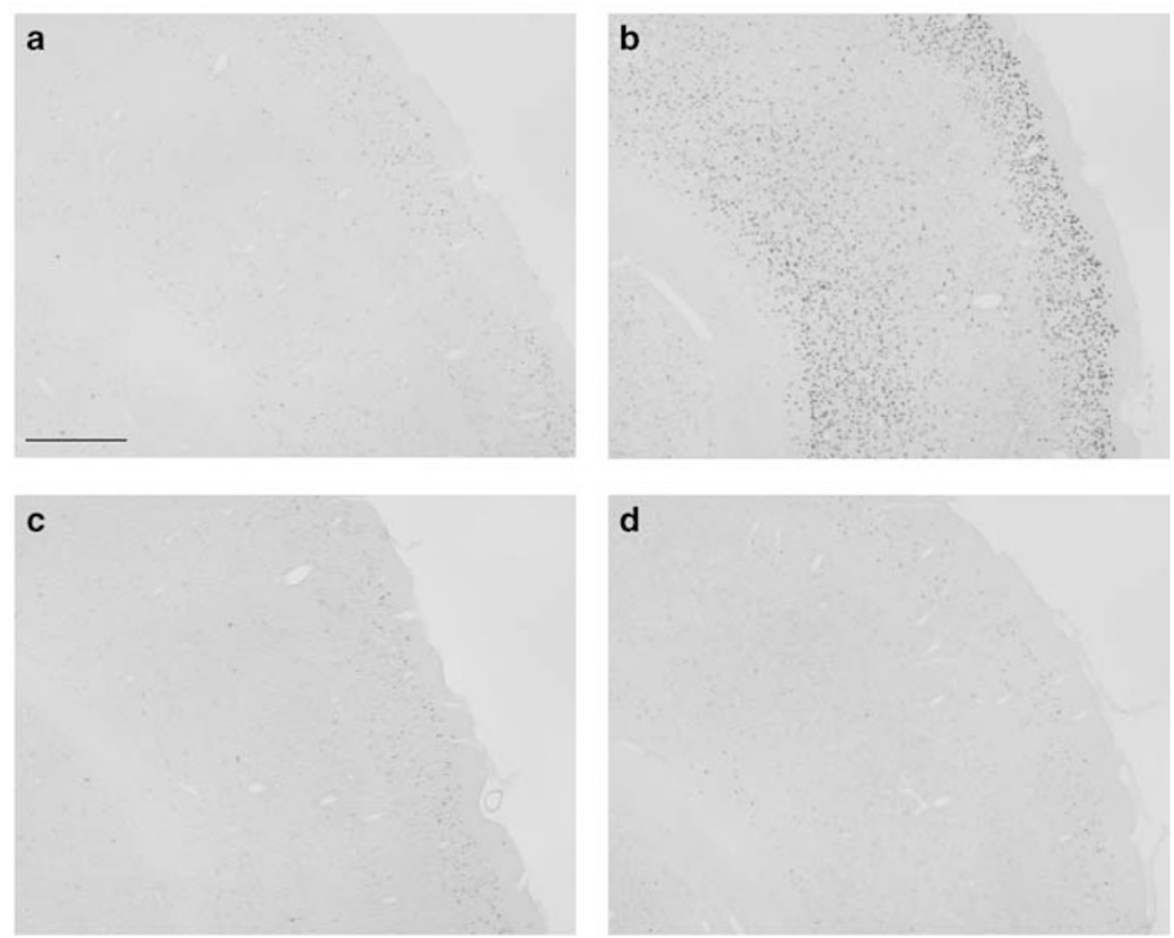

Figure 3 Representative photomicrographs of $\Delta \mathrm{Fos} B(\mathrm{~N})$ immunoreactivity in the cortex of animals in the following treatment groups: neonatal sham (a), neonate lesion (b), young-adult sham (c), and young-adult lesion (d). Scale bar: $500 \mu \mathrm{m}$.

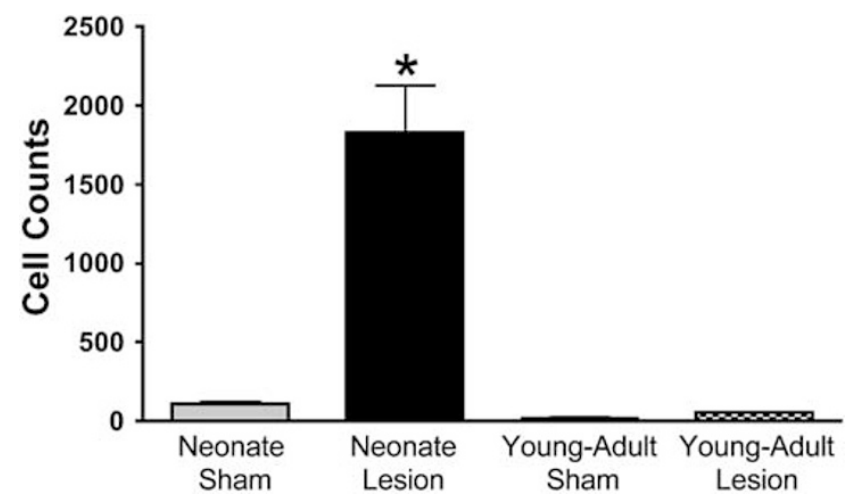

Figure 4 Effects of bilateral ibotenic acid lesions of the $\mathrm{VH}$ on $\Delta \mathrm{Fos} \mathrm{B}(\mathrm{N})$ immunoreactivity in the cortex. $\Delta \mathrm{Fos} B(\mathrm{~N})$-immunoreactive neurons were counted in 3-4 sections from four to six different animals in the neonatal sham, neonate lesion, young-adult sham, and young-adult lesion groups. Data represents mean \pm SEM cell counts. *Significantly different from neonate sham group $(* P<0.00 \mathrm{I})$.

sham lesioned controls with counts of $127.4 \pm 43.5$ and $15.4 \pm 12.0$, respectively (Figure $7 \mathrm{~b}$ ). $\Delta \mathrm{FosB}$ expression was not significantly elevated in animals lesioned as youngadults compared to sham lesioned controls with counts of $18.5 \pm 8.5$ and $8.8 \pm 3.0$, respectively (Figure $7 \mathrm{~b}$ ).

\section{Effect of Bilateral Ventral Hippocampal Lesions on $\Delta$ FosB-Like Immunoreactivity in the Nucleus Accumbens}

In all groups, a greater number of $\Delta$ FosB-immunoreactive neurons were observed in the core as compared to the shell region of the nucleus accumbens (Figure 8). Regardless of whether animals were sham treated or lesioned as neonates, a greater number of $\Delta$ FosB neurons were detected in adult animals that received these treatments as neonates as compared to young-adults (Figures $7 c$, d, and 8). Unlike the cortex and caudate putamen where neonatal lesioned animals displayed higher levels of $\Delta$ FosB expression, cell counts revealed that there was not a significant effect of Age, Lesion, or an interaction of Age $\times$ Lesion in the core of the nucleus accumbens among the four treatment groups. Lastly, in the shell region, there was a significant effect of Age $\left(\mathrm{F}_{1,16}=5.68, P<0.05\right)$ but not of Lesion or Age $\times$ Lesion, suggesting that animals sham treated or lesioned as neonates display increased $\Delta$ FosB levels compared to animals that received either treatment as young-adults. No differences were found between individual groups when post hoc comparisons were performed.

\section{DISCUSSION}

The major finding of the present study was that adult rats given $\mathrm{VH}$ lesions as neonates display a widespread and dramatic increase in the expression of $\Delta$ FosB-like proteins in the cortex, caudate putamen, and nucleus accumbens. This elevation of $\Delta$ FosB expression in the cortex and caudate putamen emerges following a maturation period since it was observed only in animals lesioned as neonates and not as young-adults. This result suggests that chronic activation of neurons, at least in terms of gene expression, in the cortex and caudate putamen may be a specific neurodevelopmental consequence of the neonatal $\mathrm{VH}$ lesion. 

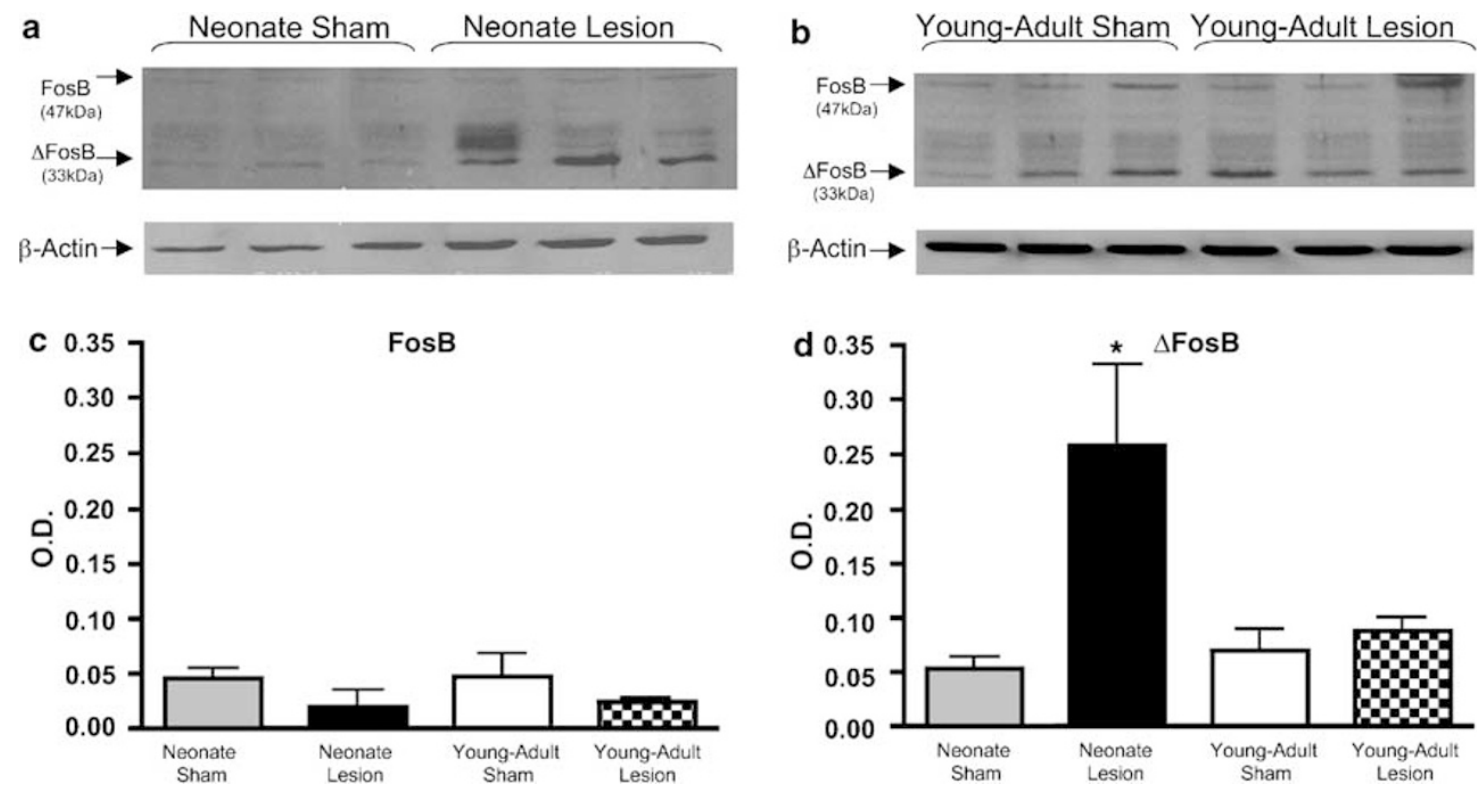

Figure 5 Representative Western blot for FosB, $\Delta$ FosB, and $\beta$-actin from cortical nuclear extracts from neonatal sham and lesioned animals (a) and from young-adult sham and lesioned animals (b). Quantification of the optical density of FosB (c) and $\Delta$ FosB (d) normalized to $\beta$-actin. Data represent mean \pm SEM optical density. *Significantly different from neonate sham group $(P<0.0 \mathrm{I})$.
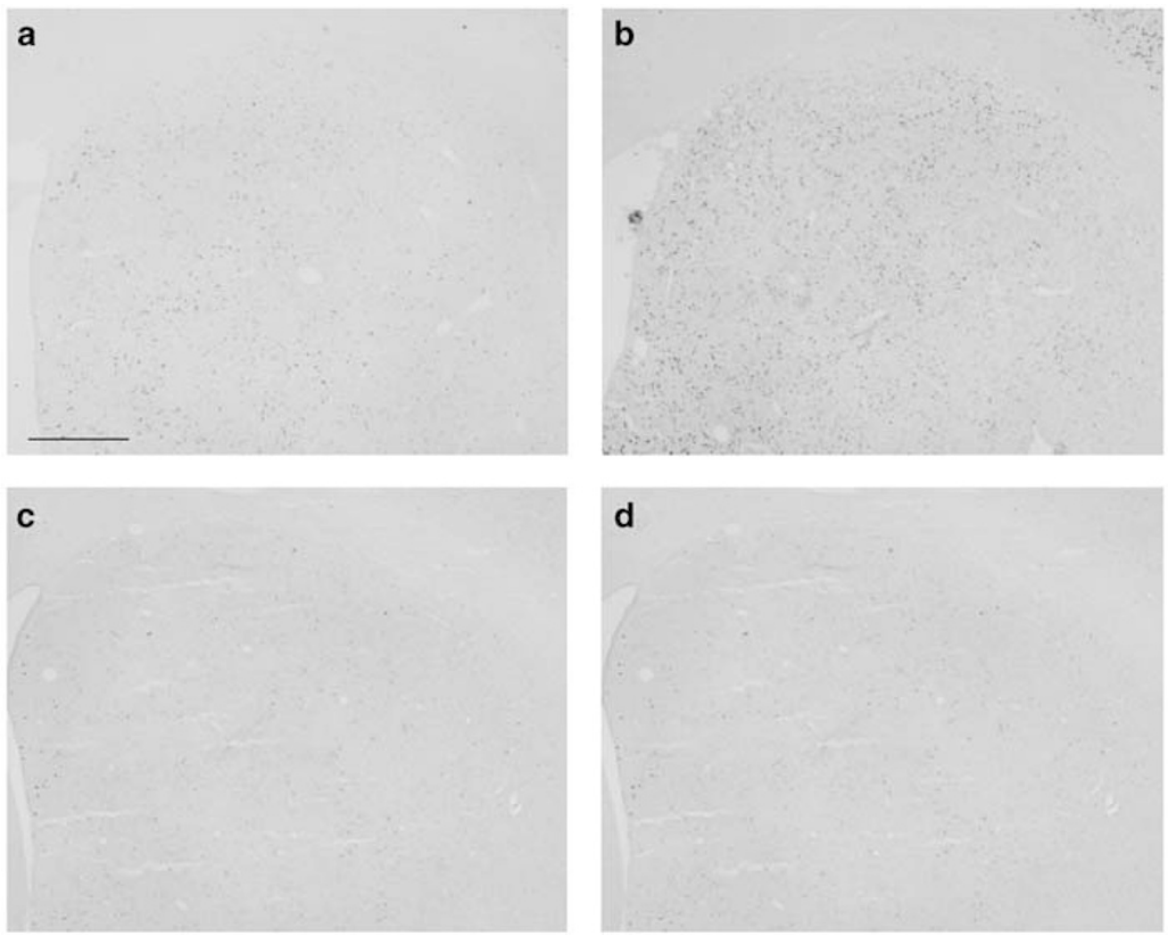

Figure 6 Representative photomicrographs of $\Delta \mathrm{Fos} B(\mathrm{~N})$ immunoreactivity in the caudate putamen from animals in the following treatment groups: neonatal sham (a), neonate lesion (b), young-adult sham (c), and young-adult lesion (d). Scale bar: $500 \mu \mathrm{m}$.

\section{Functional Implications of $\Delta$ FosB Expression}

$\Delta$ FosB-like proteins and chronic Fos-related antigens (FRAs) are long half-life transcription factors, which are induced in the brain after a variety of chronic stimuli including repeated electroconvulsive shock (Hope et al, 1994a), kainate-induced status epilepticus (Bing et al, 1996;
Mandelzys et al, 1997), chronic administration of cocaine (Hope et al, 1994b; Moratalla et al, 1996; Nye and Nestler, 1996), morphine (Nye and Nestler, 1996), nicotine (Pich et al, 1997), neuroleptics (Doucet et al, 1996; Hiroi and Graybiel, 1996; Nye et al, 1995; VahidAnsari et al, 1996), and dopaminergic deafferentation of the striatum (Doucet et al, 1996; Jian et al, 1993). It is now well established that 

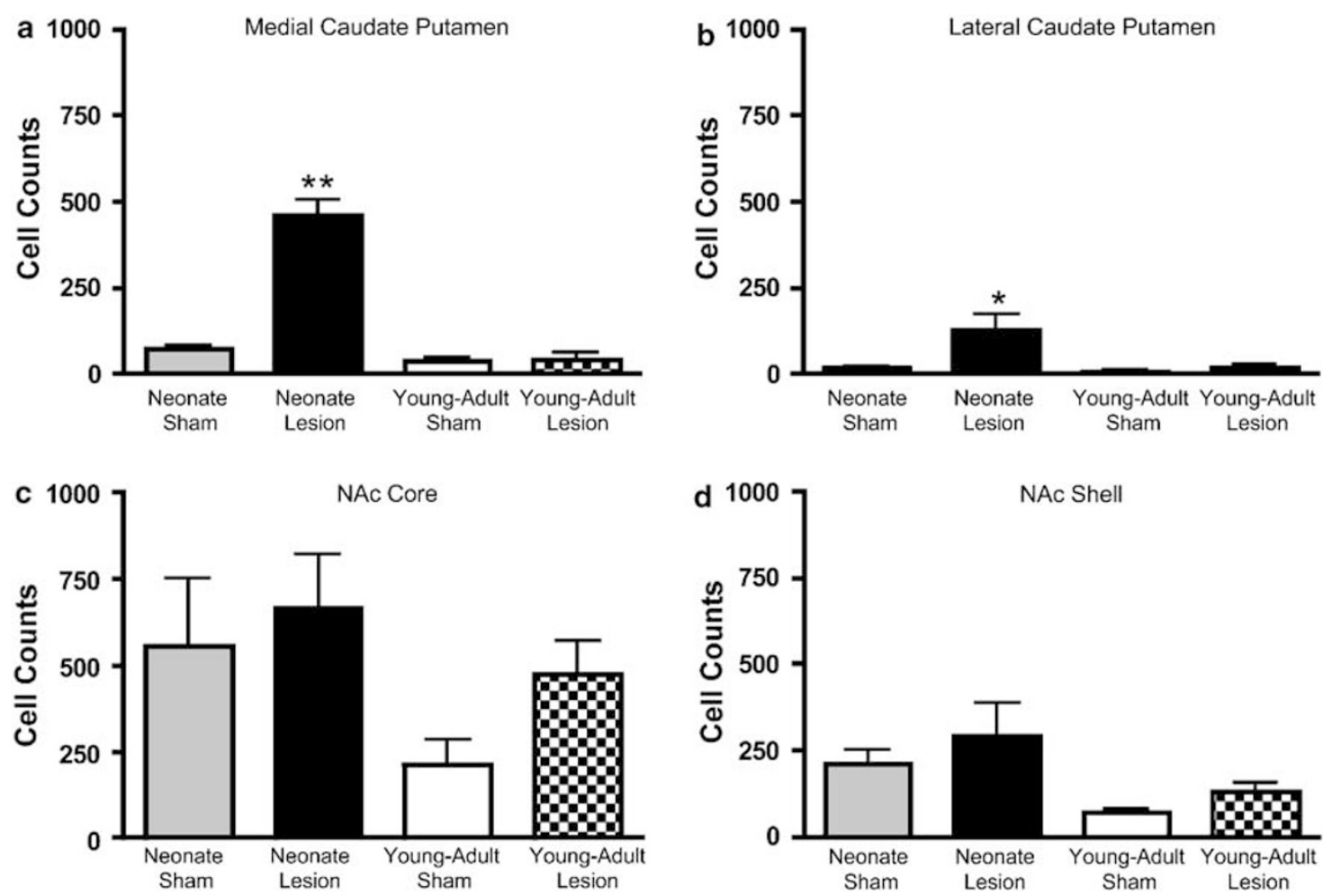

Figure 7 Effects of ibotenic acid lesions of the $\mathrm{VH}$ on $\Delta \mathrm{Fos} B(\mathrm{~N})$ immunoreactivity in the medial (a) and lateral (b) caudate putamen and the core (c) and shell (d) of the nucleus accumbens (NAc). $\Delta$ Fos-B(N)-immunoreactive neurons were counted in 3-4 sections from four to six different animals in the neonatal sham, neonate lesion, young-adult sham, and young-adult lesion groups. Data represents mean \pm SEM cell counts. *Significantly different from neonate sham group $(* P<0.01$, **P $<0.001)$.
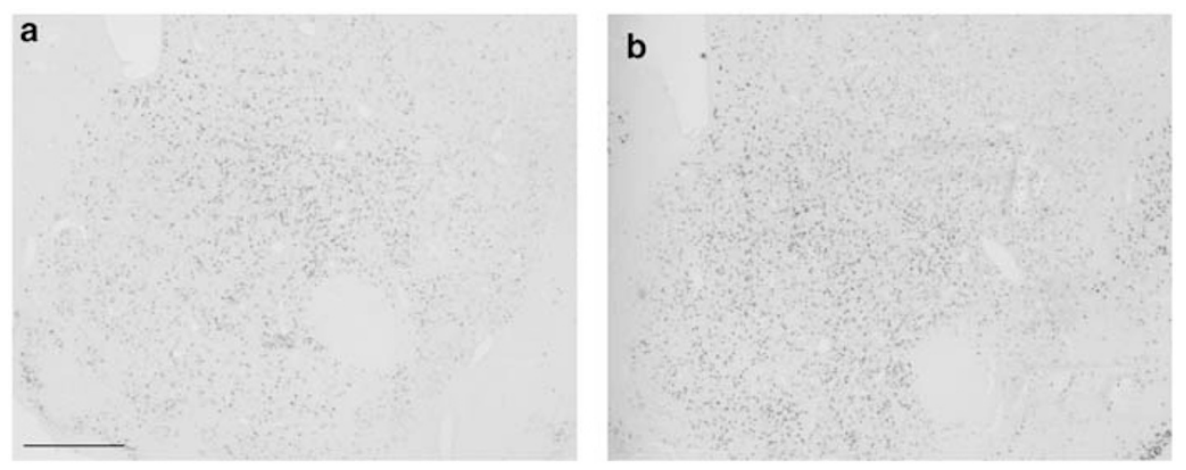

C

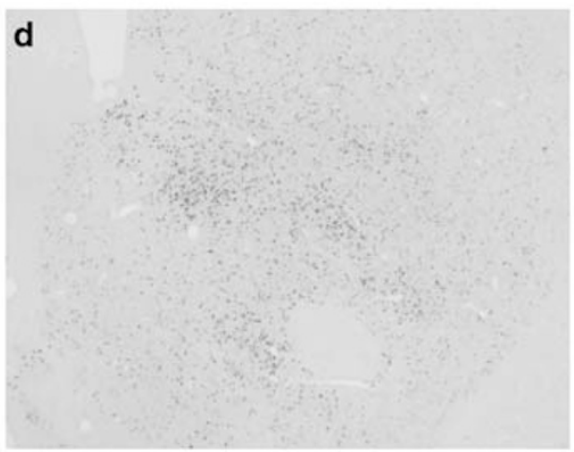

Figure 8 Representative photomicrographs of $\Delta \mathrm{Fos} B(\mathrm{~N})$ immunoreactivity in the nucleus accumbens from animals in the following treatment groups: neonatal sham (a), neonate lesion (b), young-adult sham (c), and young-adult lesion (d). Scale bar: $500 \mu \mathrm{m}$.

chronic FRAs are in fact variants of $\Delta$ FosB (Chen et al, 1997; Hiroi et al, 1997; Mandelzys et al, 1997). The hypothesis that overstimulated cells convert FosB to $\triangle \mathrm{FosB}$ as part of a cellular transcriptional 'braking system' is based, in part, on transfection assays where $\Delta$ FosB inhibited activator protein-1 (AP-1, formed by the dimerization of Fos and Jun 
proteins) transcriptional activity in a dominant-negative fashion (Nakabeppu and Nathans, 1991). Because $\Delta$ FosB has low transactivating activity, likely due to the loss of the heptaproline sequence that functions as an activation domain in FosB (Nakabeppu and Nathans, 1991), but retains the ability to both dimerize with other members of the Jun family of proteins (to form AP-1 complexes) and to bind to the AP-1 site, it competes with Fos and Jun transcription factors to form less transcriptionally active AP-1 complexes (for review see Hughes and Dragunow, 1995).

Recently, the effects of $\Delta$ FosB expression were examined in vivo using transgenic mice in which $\Delta$ FosB can be selectively induced in the brain. These studies demonstrate that short-term $\Delta$ FosB expression decreases the expression of genes by acting as a transcriptional repressor of the AP-1 site, but following prolonged expression, $\Delta$ FosB acts as a transcriptional activator at AP-1 sites (McClung and Nestler, 2003). One of the genes activated by $\Delta$ FosB is CaM-KinaseII that phosphorylates the transcription factor CREB thereby reducing the transcriptional activity of CREB and the expression of target genes (McClung and Nestler, 2003). $\Delta$ FosB also upregulates the expression of many genes that encode inhibitory ion channels or are associated with these proteins (McClung and Nestler, 2003). Further evidence that $\triangle$ FosB expression serves to reduce neuronal activity comes from the fact that repeated electroconvulsive shock both induces $\Delta$ FosB (Hope et al, 1994a) and increases resistance to subsequent seizures. Furthermore, fos $B$ knockout mice are actually predisposed to seizures (Gruda et al, 1996; Mandelzys et al, 1997). Cumulatively, these studies provide support for a dual regulatory role of $\Delta$ FosB over gene expression that changes over time and that ultimately serves to decrease cellular overactivity.

While a variety of mechanisms can be postulated to account for the widespread $\Delta$ FosB induction resulting from neonatal VH lesions, the precise pathways and neurochemical events underlying this cortical activation are not known. It has been shown that animals with neonatal $\mathrm{VH}$ lesions display profound morphological, biochemical, and electrophysiological alterations in the neurons in the medial prefrontal cortex (mPFC). Morphological changes include decreased dendritic length and spine density of pyramidal neurons (Lipska et al, 2001). Electrophysiological studies indicate that the prefrontal cortical neurons of adult rats lesioned as neonates in the $\mathrm{VH}$ are hyper-responsive to the stimulation of the VTA (O'Donnell et al, 2002). A decrease in the mRNA expression for the enzyme responsible for GABA synthesis (GAD67) has been found in the mPFC following lesion of the $\mathrm{VH}$ (Lipska et al, 2003), suggesting that attenuated GABAergic inhibition may contribute to the enhanced sensitivity of cortical neurons to VTA stimulation. Further evidence for the alterations in the mPFC following neonatal $\mathrm{VH}$ lesion comes from a study demonstrating that subsequent lesion of the mPFC as adults normalizes hyperdopaminergic behaviors observed in these animals (Lipska et al, 1998). Thus, early damage in the $\mathrm{VH}$ appears to disrupt normal cortical function and contribute to the dysregulation of subcortical dopamine neurotransmission. Prolonged increases in cortical activity may result in elevated expression of $\Delta$ FosB and reflect an attempt to compensate for excessive activation of the cortex.
It has been well documented that adult rats that have sustained neonatal $\mathrm{VH}$ lesions show an altered response to stress. These animals demonstrate a hyper-responsiveness to stress (Lipska et al, 1993) that may be mediated by an altered neuroendocrine response to stress (Chrapusta et al, 2003; Mitchell and Goldman, 2004). It is thought that the $\mathrm{VH}$ modulates the hypothalamic-pituitary-adrenal axis, producing an inhibition of this pathway following stress (Herman et al, 1998; Mitchell and Goldman, 2004). Interestingly, it has recently been shown that chronic stress increases the expression of $\Delta F$ FosB in several of the brain regions in which we observed an increase in $\Delta$ FosB following neonatal $\mathrm{VH}$ lesions, such as the mPFC, caudate putamen, and nucleus accumbens (Perrotti et al, 2004). It is therefore possible that $\mathrm{VH}$ lesions produce a state of enhanced responsiveness to stress resulting in comparable alterations in the activity or neuroendocrine and neuronal pathways that mediate stress-induced increase in $\Delta F o s B$ expression.

Antipsychotic drugs ameliorate several of the behavioral abnormalities observed in the neonatal VH lesion model of schizophrenia. These drugs also increase the expression of FosB in many of the same brain structures that we have observed in this study (Atkins et al, 1999; Robertson et al, 2004; Rodriguez et al, 2001). Despite these apparent similarities, there are several marked differences in both the pattern and magnitude of $\Delta$ FosB expression induced by neuroleptics and in the increase we observed following neonatal VH lesion. Firstly, typical neuroleptics increase $\Delta$ FosB primarily in lateral regions of the caudate putamen, while we observed a considerably greater elevation of the transcriptional regulating factor in the medial compared to the lateral aspect of dorsal caudate putamen. Secondly, chronic administration of atypical antipsychotics such as clozapine and olanzapine induces a small but significant elevation of $\Delta$ FosB immunoreactivity in the medial aspect of the caudate putamen that is located predominantly in patches (Grande et al, 2004). By contrast, neonatal VH lesions produced a considerably larger (six-fold) elevation in the number of $\Delta$ FosB-immunoreactive neurons in the medial caudate putamen that appeared to be distributed evenly, suggesting that localization is not restricted to the striatal patches. Thirdly, the increases in cortical $\Delta$ FosB expression produced by chronic neuroleptic administration are modest (two- to three-fold) and occur chiefly in frontal and cingulate regions of the cortex (Rodriguez et al, 2001), while we observed considerably larger increases in immunoreactive neurons (18-fold) localized in both superficial and deep layers throughout the entire perimeter of the neocortex. Consequently, antipsychotic drugs and neonatal $\mathrm{VH}$ lesions appear to impact different populations of neurons in the caudate putamen and cortex to a greater degree.

\section{Relationship to Clinical Findings}

Accumulating evidence implicates the hippocampus (and other temporal lobe structures) as a site of pathology in schizophrenia (Weinberger, 1999; for review of structural changes, see Shenton, 1996). Although the neuropathology of schizophrenia is obviously much more subtle than that produced by an ibotenic acid of the $\mathrm{VH}$, there may in fact be 
a clinical correlate for the cortical overactivity suggested by the marked and widespread elevation of $\Delta$ FosB expression observed in the present study. Recent post-mortem studies of patients with schizophrenia have shown a reduction in GAD67 mRNA expression in cortex (Akbarian et al, 1995; Volk et al, 2000) as well as increased GABA-A receptor binding in the prefrontal and cingulate cortices (Benes et al, 1992, 1996). Elevated GABA-A binding may reflect a compensatory response to decreased GABA synthesis designed to reverse excessive neuronal activity. More striking, however, is the laminar similarity between the cortical $\triangle$ FosB expression in our preclinical model and the pattern of GABA-A receptor upregulation observed in superficial and deep layers of the prefrontal cortex of schizophrenia patients, with the greater upregulation of both GABA-A and $\triangle$ FosB appearing to occur in lamina II (Benes et al, 1996).

In summary, the results of the present study suggest that neonatal damage to the $\mathrm{VH}$ produces a prolonged overactivation of neurons located in the caudate putamen and superficial and deep layers of the cortex that may contribute to the abnormalities observed in this model of schizophrenia. The induction of $\Delta$ FosB expression in superficial and deep layers of the neocortex may indicate an attempt to normalize activity in these neurons. Since antipsychotics ameliorate several of the behavioral abnormalities observed in the neonatal VH lesion model as well as in schizophrenia and induce FosB and $\Delta$ FosB, their mechanism may be related to long-lasting changes in gene expression regulated by Fos proteins. It would be worthwhile to determine whether chronic antipsychotic administration alters the pattern of $\Delta$ FosB expression in the cortex, nucleus accumbens, and caudate putamen that we have observed in adult animals that have sustained bilateral $\mathrm{VH}$ lesions as neonates.

\section{ACKNOWLEDGEMENTS}

This work was supported by a grant from the Ontario Mental Health Foundation. KJP was supported by a postdoctoral fellowship from the Canadian Institutes of Health Research/Institute of Neurosciences, Mental Health and Addiction/Estate of Betty Irene West. TLB received support from the Associates in Psychiatry at the Ottawa General Hospital. GSR is supported by a CIHR-Rx\&D Chair. We thank Zin Khaing and Ms Y Zhu for their excellent technical assistance.

\section{REFERENCES}

Akbarian S, Bunney WE, Potkin SG, Wigal SB, Hagman JO, Sandman CA et al (1993a). Altered distribution of nicotinamideadenine dinucleotide phosphate diaphorase cells in frontal-lobe of schizophrenics implies disturbances of cortical development. Arch Gen Psychiatry 50: 169-177.

Akbarian S, Kim JJ, Potkin SG, Hagman JO, Tafazzoli A, Bunney WE et al (1995). Gene-expression for glutamic-acid decarboxylase is reduced without loss of neurons in prefrontal cortex of schizophrenics. Arch Gen Psychiatry 52: 258-266.

Akbarian S, Vinuela A, Kim JJ, Potkin SG, Bunney WE, Jones EG (1993b). Distorted distribution of nicotinamide-adenine dinucleotide phosphate diaphorase neurons in temporal-lobe of schizophrenics implies anomalous cortical development. Arch Gen Psychiatry 50: 178-187.

Al-Amin HA, Weinberger DR, Lipska BL (2000). Exaggerated MK801 -induced motor hyperactivity in rats with the neonatal lesion of the ventral hippocampus. Behav Pharmacol 11: 269-278.

Arnold SE, Hyman BT, Vanhoesen GW, Damasio AR (1991). Some cytoarchitectural abnormalities of the entorhinal cortex in schizophrenia. Arch Gen Psychiatry 48: 625-632.

Atkins JB, Chlan-Fourney J, Nye HE, Hiroi N, Carlezon WA, Nestler EJ (1999). Region-specific induction of Delta FosB by repeated administration of typical versus atypical antipsychotic drugs. Synapse 33: 118-128.

Benes FM, Vincent SL, Alsterberg G, Bird ED, Sangiovanni JP (1992). Increased GABA-A receptor-binding in superficial layers of cingulate cortex in schizophrenics. J Neurosci 12: 924-929.

Benes FM, Vincent SL, Marie A, Khan Y (1996). Up-regulation of $\mathrm{GABA}(\mathrm{A})$ receptor binding on neurons of the prefrontal cortex in schizophrenic subjects. Neuroscience 75: 1021-1031.

Bing G, McMillian M, Kim H, Pennypacker K, Feng Z, Qi Q et al (1996). Long-term expression of the $35000 \mathrm{~mol} \mathrm{wt}$ fos-related antigen in rat brain after kainic acid treatment. Neuroscience 73: $1159-1174$.

Chen J, Kelz MB, Hope BT, Nakabeppu Y, Nestler EJ (1997). Chronic Fos-related antigens: stable variants of deltaFosB induced in brain by chronic treatments. J Neurosci 17: 4933-4941.

Chrapusta SJ, Egan MF, Wyatt RJ, Weinberger DR, Lipska BK (2003). Neonatal ventral hippocampal damage modifies serum corticosterone and dopamine release responses to acute footshock in adult Sprague-Dawley rats. Synapse 47: 270-277.

Doucet JP, Nakabeppu Y, Bedard PJ, Hope BT, Nestler EJ, Jasmin BJ et al (1996). Chronic alterations in dopaminergic neurotransmission produce a persistent elevation of Delta FosB-like protein(s) in both the rodent and primate striatum. Eur $J$ Neurosci 8: 365-381.

Dragunow M, Faull R (1989). The use of c-Fos as a metabolic marker in neuronal pathway tracing. J Neurosci Methods 29: 261-265.

Falkai PG, Bogarts B (1996). The neuropathological basis of schizophrenia. In: Waddington JL, Buckley PF (eds). The Neurodevelopmental Basis of Schizophrenia. RG Landes Company: Georgetown. pp 135-152.

Goldman PS (1971). Atypical and typical neuroleptic treatments induce distinct programs of transcription factor expression in the striatum. Exp Neurol 32: 366-387.

Grande $\mathrm{C}$, Zhu $\mathrm{H}$, Martin $\mathrm{AB}$, Lee $\mathrm{M}$, Ortiz O, Hiroi $\mathrm{N}$ et al (2004). Chronic treatment with atypical neuroleptics induces striosomal FosB/ $\Delta$ FosB expression in rats. Biol Psychiatry 55: 457-463.

Gruda MC, vanAmsterdam J, Rizzo CA, Durham SK, Lira S, Bravo R (1996). Expression of FosB during mouse development: normal development of FosB knockout mice. Oncogene 12: 2177-2185.

Herman JP, Dolgas CM, Carlson SL (1998). Ventral subiculum regulates hypothalamo-pituitary-adrenocortical and behavioral responses to cognitive stressors. Neuroscience 86: 449-459.

Hiroi N, Brown JR, Haile CN, Ye H, Greenberg ME, Nestler EJ (1997). FosB mutant mice: loss of chronic cocaine induction of Fos-related proteins and heightened sensitivity to cocaine's psychomotor and rewarding effects. Proc Natl Acad Sci USA 94: 10397-10402.

Hiroi N, Graybiel AM (1996). Atypical and typical neuroleptic treatments induce distinct programs of transcription factor expression in the striatum. J Comp Neurol 374: 70-83.

Hope BT, Kelz MB, Duman RS, Nestler EJ (1994a). Chronic electroconvulsive seizure (ecs) treatment results in expression of a long-lasting AP-1 complex in brain with altered composition and characteristics. J Neurosci 14: 4318-4328. 
Hope BT, Nye HE, Kelz MB, Self DW, Iadarola MJ, Nakabeppu Y et al (1994b). Induction of a long-lasting ap-1 complex composed of altered fos-like proteins in brain by chronic cocaine and other chronic treatments. Neuron 13: 1235-1244.

Hughes P, Dragunow M (1995). Induction of immediate-early genes and the control of neurotransmitter-regulated geneexpression within the nervous-system. Pharmacol Rev 47: 133-178.

Jakob H, Beckmann H (1986). Prenatal developmental disturbances in the limbic allocortex in schizophrenics. J Neural Transm 65: 303-326.

Jian M, Staines WA, Iadarola MJ, Robertson GS (1993). Destruction of the nigrostriatal pathway increases fos-like immunoreactivity predominantly in striatopallidal neurons. Mol Brain Res 19: 156-160.

Kolb B, Whishaw IQ (1989). Plasticity in the neocortex - mechanisms underlying recovery from early brain-damage. Prog Neurobiol 32: 235-276.

Lipska BK, Al Amin HA, Weinberger DR (1998). Excitotoxic lesions of the rat medial prefrontal cortex - effects on abnormal behaviors associated with neonatal hippocampal damage. Neuropsychopharmacology 19: 451-464.

Lipska BK, Jaskiw GE, Chrapusta S, Karoum F, Weinberger DR (1992). Ibotenic acid of the ventral hippocampus differentially affects dopamine and its metabolites in the nucleus accumbens and prefrontal cortex in the rat. Brain Res 585: 1-6.

Lipska BK, Jaskiw GE, Weinberger DR (1993). Postpubertal emergence of hyperresponsiveness to stress and to amphetamine after neonatal excitotoxic hippocampal damage - a potential animal-model of schizophrenia. Neuropsychopharmacology 9: 67-75.

Lipska BK, Kolb B, Halim N, Weinberger DR (2001). Synaptic abnormalities in prefrontal cortex and nucleus accumbens of adult rats with neonatal hippocampal damage. Schizophr Res 49: 47.

Lipska BK, Lerman DN, Khaing ZZ, Weickert CS, Weinberger DR (2003). Gene expression in dopamine and GABA systems in an animal model of schizophrenia: effects of antipsychotic drugs. Eur J Neurosci 18: 391-402.

Lipska BK, Swerdlow NR, Geyer MA, Jaskiw GE, Braff DL, Weinberger DR (1995). Neonatal excitotoxic hippocampal damage in rats causes post pubertal changes in prepulse inhibition of startle and its disruption by apomorphine. Psychopharmacology 122: 35-43.

Lipska BK, Weinberger DR (1993). Delayed-effects of neonatal hippocampal damage on haloperidol-induced catalepsy and apomorphine-induced stereotypic behaviors in the rat. Dev Brain Res 75: 213-222.

Lipska BK, Weinberger DR (1994). Subchronic treatment with haloperidol and clozapine in rats with neonatal excitotoxic hippocampal damage. Neuropsychopharmacology 10: 199-205.

Mandelzys A, Gruda MA, Bravo R, Morgan JI (1997). Absence of a persistently elevated $37 \mathrm{kDa}$ fos-related antigen and AP-1-like DNA-binding activity in the brains of kainic acid-treated fosB null mice. J Neurosci 17: 5407-5415.

McClung CA, Nestler EJ (2003). Regulation of gene expression and cocaine reward by CREB and Delta FosB. Nat Neurosci 6: 1208-1215.

Mitchell CP, Goldman MB (2004). Neonatal lesions of the ventral hippocampal formation disrupt neuroendocrine responses to auditory stress in the adult rat. Psychoneuroendocrinology 29: $1317-1325$.

Moratalla R, Elibol B, Vallejo M, Graybiel AM (1996). Networklevel changes in expression of inducible Fos-Jun proteins in the striatum during chronic cocaine treatment and withdrawal. Neuron 17: 147-156.

Morgan JI, Curran T (1989). Stimulus-transcription coupling in neurons - role of cellular immediate-early genes. Trends Neurosci 12: 459-462.
Morgan JI, Curran T (1991). Stimulus-transcription coupling in the nervous-system - involvement of the inducible protooncogenes Fos and Jun. Annu Rev Neurosci 14: 421-451.

Mumberg D, Lucibello FC, Schuermann M, Muller R (1991). Alternative splicing of fosb transcripts results in differentially expressed messenger-RNAs encoding functionally antagonistic proteins. Genes Dev 5: 1212-1223.

Nakabeppu Y, Nathans D (1991). A naturally-occurring truncated form of fosb that inhibits fos jun transcriptional activity. Cell 64: 751-759.

Nakabeppu Y, Oda S, Sekiguchi M (1993). Proliferative activation of quiescent rat-1A cells by delta-fosb. Mol Cell Biol 13: $4157-4166$.

Nye HE, Hope BT, Kelz MB, Iadarola M, Nestler EJ (1995). Pharmacological studies of the regulation of chronic FOS-related antigen induction by cocaine in the striatum and nucleus accumbens. J Pharmacol Exp Ther 275: 1671-1680.

Nye HE, Nestler EJ (1996). Induction of chronic fos-related antigens in rat brain by chronic morphine administration. Mol Pharmacol 49: 636-645.

O'Donnell P, Lewis BL, Weinberger DR, Lipska BK (2002). Neonatal hippocampal damage alters electrophysiological properties of prefrontal cortical neurons in adult rats. Cerebr Cortex 12 : 975-982.

Perrotti LI, Hadeishi Y, Ulery PR, Barrot M, Monteggia L, Duman RS et al (2004). Induction of $\Delta$ FosB in reward-related brain structures after chronic stress. J Neurosci 24: 10594-10602.

Pich EM, Pagliusi SR, Tessari M, TalabotAyer D, vanHuijsduijnen RH, Chiamulera C (1997). Common neural substrates for the addictive properties of nicotine and cocaine. Science 275: 83-86.

Robertson GS, Fibiger HC (1992). Neuroleptics increase c-fos expression in the forebrain: contrasting effects of haloperidol and clozapine. Neuroscience 46: 315-328.

Robertson GS, Lee CJ, Sridhar K, Nakabeppu Y, Cheng M, Wang YM et al (2004). Clozapine-, but not haloperidol-, induced increases in Delta FosB-like immunoreactivity are completely blocked in the striatum of mice lacking D3 dopamine receptors. Eur J Neurosci 20: 3189-3194.

Rodriguez JJ, Garcia DR, Nakabeppu Y, Pickel VM (2001). Enhancement of laminar FosB expression in frontal cortex of rats receiving long chronic clozapine administration. Exp Neurol 168: 392-401.

Rosen JB, Chuang E, Iadarola MJ (1994). Differential induction of fos protein and a fos-related antigen following acute and repeated cocaine administration. Mol Brain Res 25: 168-172.

Sagar SM, Sharp FR, Curran T (1988). Expression of c-fos protein in brain-metabolic mapping at the cellular-level. Science 240: $1328-1331$.

Sheng M, Greenberg ME (1990). The regulation and function of c-fos and other immediate early genes in the nervous-system. Neuron 4: 477-485.

Shenton ME (1996). Temporal lobe structural abnormalities in schizophrenia: a selective review and presentation of new magnetic resonance findings. In: Matthysse S, Levy DL, Kagan J, Benes FM (eds). Psychopathology: The Evolving Science of Mental Disorder. Press Syndicate of the University of Cambridge: Cambridge. pp 51-99.

VahidAnsari F, Nakabeppu Y, Robertson GS (1996). Contrasting effects of chronic clozapine, Seroquel(TM) (ICI 204,636) and haloperidol administration on Delta FosB-like immunoreactivity in the rodent forebrain. Eur J Neurosci 8: 927-936.

vanPraag $\mathrm{H}$, Alberch J, PerezNavarro E, Wu H, Qu PM, Black IB et al (1996). Unilateral neonatal hippocampal lesion alters septal innervation and trophism of the entorhinal cortex. Exp Neurol 141: $130-140$.

Volk DW, Austin MC, Pierri JN, Sampson AR, Lewis DA (2000). Decreased glutamic acid decarboxylase(67) messenger RNA 
expression in a subset of prefrontal cortical gamma-aminobutyric acid neurons in subjects with schizophrenia. Arch Gen Psychiatry 57: 237-245.

Walker EF, Neumann CS (1996). Neurodevelopmental models of schizophrenia: the role of central nervous system maturation in the expression of neuropathology. In: Waddington JL, Buckley PF (eds). The Neurodevelopmental Basis of Schizophrenia. RG Landes Company: Austin. pp 1-16.
Weinberger DR (1987). Implications of normal brain development for the pathogenesis of schizophrenia. Arch Gen Psychiatry 44: 660-669.

Weinberger DR (1996). On the plausibility of 'The neurodevelopmental hypothesis' of schizophrenia. Neuropsychopharmacology 14: S1-S11.

Weinberger DR (1999). Cell biology of the hippocampal formation in schizophrenia. Biol Psychiatry 45: 395-402. 